\title{
Lapses of Attention in Medical Malpractice and Road Accidents
}

\begin{abstract}
Robert Cooter and Ariel Porat*
A doctor who lapses and injures her patient, and a driver who lapses and causes an accident, are liable under negligence law for the harm done. But lapse is not necessarily negligence, since reasonable people lapse from time to time. We show that tort liability for "reasonable" lapses distorts doctors', drivers', and manufacturers' incentives to take care. Furthermore, such liability provides potential injurers with incentives to substitute activities which are less prone to lapses with activities which are more prone to lapses, even if such substitution is inefficient. We propose several solutions to the inefficiencies that result from liability for lapses, and argue that under certain circumstances injurers should be entitled to invoke a "lapse defense."
\end{abstract}

\section{INTRODUCTION}

When making a decision and executing it, harm can result from misjudged distances, underestimated probabilities, unforeseen consequences, quavering hands, slips of the tongue, clumsy feet, or an eye's blink. Given the possibility of lapses, actors cannot simply choose a specific level of precaution. Instead, they draw their precaution from a probability distribution. Here is an example.

Example 1: Driver's Lapse. A motorist sets out on the long, straight drive from San Francisco to Los Angeles on Route 5. The speed limit

* Robert Cooter is Herman Selvin Professor of Law, University of California at Berkeley. Ariel Porat is Alain Poher Professor of Law, Tel Aviv University, and Fischel-Neil Distinguished Visiting Professor of Law, University of Chicago. For helpful comments we thank Jennifer Arlen, Ronen Avraham, Israel Gilead, Assaf Jacob, Eric Posner, Noam Sher and the participants of the Cegla conference on New Approaches for a Healthier and Safer Society. We also thank Arik Brenneisen and Roni Schocken for very able research assistance, and Yael Braudo, Yaniv Hassidim, Idit Deutch, Yair Laron, and Stass Tsirulnik for excellent editorial work. 
is seventy miles per hour, which is also the reasonable speed. The car lacks a mechanical device to maintain constant speed ("cruise control"). The driver aims for sixty-five miles per hour. Not being a machine, the driver cannot possibly go sixty-five all the time. The driver makes a reasonable effort to maintain constant speed, but occasional lapses in attention cause the driver to exceed or fall short of sixty-five. Near the end of the trip, the driver has an accident while going seventy-three. He would have avoided the accident if he had been going seventy or less. In statistical terms, the driver in this example draws his speed from a probability distribution with high density around sixty-five and low density above seventy. The driver lapses when he unintentionally draws an uncharacteristically high speed from the probability distribution.

We use the term "first-order precaution" to refer to acts that directly affect the probability of an accident, such as maintaining reasonable driving speed. First-order precaution that falls short of a community standard of care constitutes negligence in common law. The possibility of a lapse makes negligence and liability probabilistic. Under the prevailing tort rule, the driver in the preceding example was negligent at the time of the accident, and his negligence caused the accident, so he is liable for the resulting harm.

While the driver in the example cannot choose an exact speed, he can affect the probability of lapsing. After beginning his journey, the probability of lapsing depends on how often the driver checks the speedometer, glances in the rearview mirror, observes the gap between his car and the car in front of him, and makes a rest stop or drinks coffee. Even before the journey begins, the driver can take driving lessons, practice going a constant speed, and get a good night's sleep before the journey. The driver can also choose his target speed, which affects the consequences of a lapse. For example, lapsing has less serious consequences when the target is sixty-five than when it is seventy. We refer to such acts that affect the probability distribution over first-order precaution or the seriousness of its consequences as "second-order precaution." In liability law, second-order precaution often takes the form of intentions, preparations, and concentration. In our terminology "second-order negligence" is a failure to take reasonable second-order precaution.

Lapses cause a high proportion of accidents, yet probabilistic precaution is under-theorized in liability law. This Article develops a theory of lapses based on the difference between first- and second-order behavior. We model first-order precaution as a draw from a probability distribution, not an exact choice. We model second-order precaution as behavior that changes the probability distribution over first-order precaution, such as concentration when 
driving and preparation for an operation. Second-order precaution reduces the probability of drawing a low level of first-order precaution.

Our focus is on the question of allowing or disallowing a second-order reasonableness defense for lapses. Under prevailing law, the injurer is liable for the harm caused by negligence of any order. ${ }^{1}$ The injurer is liable for harm caused by unreasonable first-order precaution, and the law does not allow a defense of second-order reasonableness. Allowing such a defense would eliminate inefficiencies which result from liability for unreasonable first-order but reasonable second-order behavior, as we explain below. Furthermore, even if courts were willing to apply such a defense, they would typically not be able to observe essential elements of second-order precaution unless the injurer reveals it. Thus, the court cannot obtain a GPS record unless the driver keeps it. The same is true of records of a doctor's preparation to perform an operation. Under certain conditions, modifying the prevailing tort rule to allow a defense of second-order reasonableness will cause injurers to satisfy this legal standard and to make this fact observable.

If the defense is recognized and implementable, three distinct advantages follow. First, the courts can set the legal standard to induce socially efficient second-order behavior. This is desirable when uncertainty would otherwise cause precaution to be too high or too low. Second, this defense reduces the burden of liability on the underlying activity. This is desirable for activities that benefit others ("positive externalities") such as practicing medicine, and undesirable for activities that harm others ("negative externalities") such as driving. Third, the defense will sometimes channel people away from more dangerous activities into less dangerous ones ("substitution"). ${ }^{2}$ We advocate

1 Under prevailing law, the plaintiff who cannot prove first order negligence may be able to recover by proving that second order negligence caused his harm. For example, assume that a driver swerves into the opposing lane and hits another car. If the driver swerved to avoid hitting a child, swerving may not have been negligent. First order behavior is reasonable. However, the plaintiff may be able to prove that the driver failed to stop because he did not maintain his brakes in good order. Second order behavior is unreasonable.

2 These are efficiency arguments. Liability for lapses also raises concerns from a retributive justice perspective. Consider someone who lapses no more often than other reasonable people. If the person lapses and harms someone, the injurer is arguably no worse morally than other reasonable people who did not lapse. The injurer, consequently, does not deserve a sanction in the form of tort liability: his bad luck should not count against him. Theorists who discuss the fairness (or retributive justification) of outcome responsibility (liability for materialized harms as opposed to liability for unrealized risks) often use such examples of lapses to illustrate the alleged unfairness of outcome responsibility. Their 
extending the defense of second-order reasonableness more generally, when doing so captures some of these three kinds of benefits.

The Article is organized as follows. Part I provides an account of the way prevailing tort law deals with lapses. Part II develops our behavioral model of lapses. Part III applies the model to situations where the activity creates negative or positive externalities. Part IV discusses the substitution of activities and forms of precaution that decrease the probability of a lapse but increase the overall risk of an accident. Part $V$ develops a second-order reasonableness defense and offers various ways to implement it. The Conclusion follows.

\section{Lapses Under Prevailing Tort Law}

A lapse from a legal standard of precaution is usually sufficient to trigger liability for any resulting harm. In such cases, the prevailing tort rule does not usually allow a defense of second-order reasonableness. Close inspection will reveal circumstances where courts are open to a defense of second-order reasonableness.

\section{A. Road Accidents}

In most jurisdictions, drivers are liable for harm caused by their negligence, and a driver is found negligent when his behavior is unreasonable. Examples are speeding, not stopping at a stop sign, reacting too slowly in dangerous

arguments would be stronger if they distinguished between first- and second-order negligence, and offered examples of first-order negligence without second-order negligence. See, e.g., Tony Honore, Responsibility and Luck: The Moral Basis of Strict Liability, 104 L.Q. REv. 53 (1988) (justifying outcome responsibility on fairness grounds); Christopher H. Schroeder, Corrective Justice \& Liability for Increasing Risks, 37 UCLA L. REv. 439 (1990) (arguing from a corrective justice perspective for liability for unrealized risks instead of materialized harms); Jeremy Waldron, Moments of Carelessness and Massive Loss, in PHILOsOPHICAL Foundations OF TORT LAw 387 (David G. Owen ed., 1995) (justifying outcome responsibility on the ground of retributive justice, and using an example of a lapse). For a discussion of the moral luck argument from a corrective justice perspective, see John Goldberg \& Benjamin Zipursky, Tort Law and Moral Luck, 92 CoRNELl L. REv. 1123, 1127, 1153-54 (2007) (explaining that negligence law, while counting the injurer's bad luck against him, cannot be defended on moral grounds only); Arthur Ripstein, Closing the Gap, 9 TheORETICAL INQUIRIES L. 61 (2008) (justifying liability for materialized harms only); and Benjamin C. Zipursky, Two Dimensions of Responsibility in Crime, Tort and Moral Luck, 9 THEORETICAL INQUIRIES L. 97, 98-106 (justifying negligence-based liability). 
situations, ${ }^{3}$ taking eyes off the road, ${ }^{4}$ not maintaining a proper lookout, ${ }^{5}$ failing to slow down when necessary, and not keeping an adequate distance from other cars. Lapses appear to be a common cause of unreasonable behavior of drivers, possibly the most common cause. Potentially, a driver who lapses could have raised a second-order defense by showing that he acted reasonably at an earlier stage to reduce the probability of lapsing. Courts, however, are reluctant to admit such a defense in road accidents.

In exceptional cases, however, courts refuse to consider a momentary lapse of attention as negligence per se. One such case is Plowman v. Digatono. ${ }^{6}$ In this case, the plaintiff stopped his car at a red light, proceeded forward when the light turned green, and then stopped in the intersection to avoid striking a car in front of him. Defendant, a policeman who drove a police car, ran into the rear end of plaintiff's car. The collision occurred as defendant looked away from traffic for a "moment" to hang up the microphone on his car radio. The jury found that the defendant was not negligent, and the Court of Appeals upheld the jury's decision, stating that "the district court did not err in ... allowing the jury to consider whether ... [defendant's] momentary lapse of

3 See Bobstein v. Splinter, 168 So. 2d 560 (Fla. Dist. Ct. App. 1964). In this guest statute (a statute governing the liability of a driver toward a guest in his car) case, the defendant collided into another vehicle which was not expected to be there. The majority imposed liability on the defendant toward the passenger in his car. However, the dissent was not convinced that gross negligence, which is a precondition for imposing liability on the driver under that statute, was proven. The judge reasoned that

it affirmatively appears that due either to a momentary lapse of attention, or the unnatural and unanticipated action of the driver of the other vehicle, defendant did not see such vehicle until it was too late to stop his automobile before the collision ensued. While such action on the part of defendant may constitute simple negligence, it falls far short of the standard required in order to allege gross negligence.

Id. at 563 (emphasis added).

4 See Pedersen v. Kinsley, 25 N.E.2d 567 (I11. App. Ct. 1975). In this guest statute case, the defendant driver swerved off the road and struck a lamppost. The court imposed liability on the driver, for taking her eyes off the road, and considered it not only as mere negligence, but as willful and wanton misconduct. For similar facts and same outcome, see also Rosbottom v. Hensley, 61 N.E.2d 198, 209, 655 (Ill. App. Ct. 1965).

5 See Sec. Timber \& Land Co. v. Reed, 398 So. 2d 174 (La. Ct. App. 1981). In this case, a driver was found contributory negligent for not maintaining a proper lookout, resulting in a collision with another car.

6 Plowman v. Digatono, 1995 N.W.2d 1291 (Minn. Ct. App. 1995). 
attention to replace his microphone was a reasonable excuse for his conduct."

Furthermore, in two categories of cases, drivers' lapses are typically insufficient for imposition of liability. The first category concerns guest statutes that govern the liability of a driver toward a guest in his car. Liability requires the driver's gross negligence or willful and wanton misconduct. ${ }^{8}$ Gross negligence and willful and wanton misconduct go to the quality of selfmonitoring. They often imply a knowing or deliberate choice of unreasonable second-order behavior. Consequently, under these statutes, a lapse of attention is often considered not enough to satisfy the requirements of driver's liability to a guest. ${ }^{9}$

The second category concerns sudden emergencies on roads and elsewhere. One court formulated the sudden emergency doctrine, which many courts have recognized, as follows:

One who suddenly finds himself in a position of imminent peril, without sufficient time to consider and weigh all the circumstances or best means that may be adopted to avoid an impending danger, is not guilty of negligence if he fails to adopt what subsequently and upon reflection may appear to have been a better method, unless the emergency in which he finds himself is brought about by his own negligence. ${ }^{10}$

According to this formulation, the sudden emergency doctrine does not lower the standard of care required of a motorist before the emergency occurs. ${ }^{11}$ The sudden emergency doctrine cannot be invoked by one who has brought the emergency on himself by his own wrong or who has not taken due care

$7 \quad$ Id. at 1295; see also Porter v. State, 88 S.W.2d 924, 926 (Ark. Ct. App. 2003) (a criminal case on manslaughter, in which Justice O'Connell noted that

there are few, if any, persons who drive automobiles who have not, through momentary lapse of attention, error of judgment, failing to see what they should have seen, particularly on roads not in municipalities, been guilty of running a stop sign at an intersection without slowing down. Such, no doubt, constitutes negligence sufficient to support a damage suit based on simple negligence. We doubt that it would support a verdict under our guest statute. Nor do we believe that it is sufficient to support a verdict of manslaughter.)

8 See Hoffman v. Slocum, 219 Cal. App. 2d 100, 103 (Cal. Ct. App. 1963) (imposing liability on a driver toward a guest, reasoning that "the trier of the fact was entitled to infer that this was not simply an error of judgment or a momentary lapse of attention on the driver's part"); see also Porter, 88 S.W.2d 924; Bobstein, 168 So. $2 \mathrm{~d} 560$.

$9 \quad$ But see supra note 4.

10 Hickman v. S. Pac. Trans. Co., 262 So. 2d 385, 389 (La. 1972).

11 Dick v. Phillips, 218 So. 2d 299, 302 (La. 1969). 
to avoid it. If the actor took reasonable care before the sudden emergency, then this legal doctrine lowers the standard of care applicable in the sudden emergency. In our terminology, second-order reasonableness provides a defense against liability for first-order negligence in a sudden emergency.

\section{B. Medical Malpractice}

Turning to medical malpractice, doctors are held liable for the consequences of their negligence in making decisions and executing them. Many medical accidents are the result of errors, and errors are often caused by lapses. ${ }^{12}$ Lapses in decisions result in failing to diagnose, choosing the wrong drug to administer, choosing the wrong technique to perform, using the wrong medical equipment, omitting tests needed to diagnose the patient's illness, or deciding to operate too early or too late. Lapses in execution result in administering a different drug from the one intended, incorrectly performing a medical technique, using medical equipment improperly, misreading results of diagnostic tests, operating on the wrong patient or the wrong body part, leaving a sponge inside a patient's body, failing to sterilize medical equipment, or failing to monitor the patient's condition. ${ }^{13}$

12 For a profound analysis, both positive and normative, of errors, lapses, and related occurrences in the field of medicine, see Alan Merry \& Alexander McCall Smith, Errors, Medicine and the Law 72-97, 127-51 (2006). For data on medical errors and their huge contribution to patients' injury, see Robert J. Cimasi, Medical Malpractice and Tort Reform Risks, in Insurance and Risk Management Strategies 186 (Jones \& Bartlett eds., 2005). For the argument that systemic errors are major causes of most medical accidents even if typically combined with individual errors, and for a comprehensive account of all types of medical errors based on extensive empirical evidence, see Michelle M. Mello \& David M. Studdert, Deconstructing Negligence: The Role of Individual and System Factors in Causing Medical Injuries, 96 Geo. L.J. 599 (2008).

13 For a comprehensive list of causes of patients' injury which include those mentioned in the text and many others, see JAMEs E. OrLIKOFF \& Audrone M. Vanagunas, Malpractice Prevention and Liability Control for Hospitals 65-67 (2d ed. 1988); and Mello \& Studdert, supra note 12. For case law illustrations of execution failures, see Mobile Infirmary Ass'n v. Tyler, 981 So. 2d 1077 (Ala. 2007); Powell v. Kleinman, 151 Cal. Rptr. 2 d 112 (Cal. Ct. App. 2007) (failing to ascertain results of a test administered to the patient); Rivera v. Anilesh, 869 N.E.2d 654 (N.Y. 2007) (negligent performance of injections of anesthesia and extraction of a tooth could result in dentists' liability); and Vanderpool v. Adirondack Neurosurgical Specialists, P.C., 846 N.Y.S.2d 832 (N.Y. App. Div. 2007) (failing to diagnose plaintiff's bilateral pars defect, which was evident from $\mathrm{X}$ rays and an MRI, prior to performing spinal surgery). 
Anecdotal evidence from the case law suggests that doctors are more often found liable for failures in execution than for failures in judgment. ${ }^{14}$ One reason could be implicit recognition of a second-order reasonableness defense. Thus courts sometimes exempt physicians from liability for an error of judgment if they acted in good faith. ${ }^{15}$ Good faith depends to a large extent upon second-order behavior. When doctors prepared reasonably before making a decision, courts often exempt them from liability for making the wrong decision. For example, when a doctor decides to deliver a baby by Cesarean section, courts will ordinarily not check the reasonableness of his decision so long as they are convinced he prepared properly to make it. In contrast, once the method is decided for delivering the baby, the courts are reluctant to excuse faulty execution on grounds of reasonable preparation. ${ }^{16}$

A second possible reason why courts are more hesitant in imposing liability for doctor's misjudgment is difficulties of proof. Lapses in execution are relatively easy to observe, whereas misjudgments require second-guessing. Many misjudgments remain undetected or unproved, so they do not trigger liability.

Powell v. Kleinman, decided by a Californian Court of Appeal, ${ }^{17}$ illustrates courts' inclination to find negligence more easily with regard to bad execution than with regard to bad judgment. In this case a patient sued his doctors for harms resulting from failure to diagnose promptly and treat an injury to his spinal cord. The plaintiff alleged doctors' negligence manifested in three ways:

1. The doctors initially failed to test for spinal weakness, discover weakness, or note findings of weakness. Here the doctors seem to have weighed alternatives and decided that tests were unnecessary.

14 Similarly, in the field of liability of public authorities, courts are much more willing to impose liability for execution of operational rather than discretional powers. See Cherie Booth \& Dan Squires, The Negligence Liability of Public Authorities 46-51 (2006) (distinguishing between policy and operational decisions of the public authority and indicating courts' enhanced willingness to impose liability for the latter rather than for the former).

15 See Dotson v. Hammerman, 932 S.W.2d 880 (Mo. Ct. App. 1996); David A. Hyman \& Charles Silver, Medical Malpractice Litigation and Tort Reform: It's the Incentives, Stupid, 59 VAND. L. REv. 1085, 1097 (2006) (citing several studies and stipulating that "[a]11 find that the merits matter, and some find that the merits matter more than anything else. Plaintiffs who received substandard care generally obtained compensation ... plaintiffs who received proper care generally did not ... and plaintiffs whose care quality was uncertain wound up in between.").

16 See infra Section IV.C.

17 Powell, 151 Cal. App. 4th 112. 
2. When the plaintiff's symptoms continued, the doctors decided to evaluate the patient using an MRI test, and they failed to do so.

3. The doctors allegedly decided to rely on the hospital to test for spinal cord compromise. The doctors assumed that the staff at the hospital had tested for cord compromise without confirming it had done so.

On defendant's appeal for summary judgment, the Court of Appeal faced the question whether any of the plaintiff's allegations could give rise to the doctors' liability. The Court decided that the first allegation, which concerns bad judgment, could not give rise to doctors' liability. The Court decided that the second and third allegations, which concern bad execution, could give rise to the doctors' liability.

The preceding discussion of doctrine and cases suggests that courts impose liability for faulty executions more readily than for faulty judgments. A possible explanation for that is that with judgment, but not with execution, a secondorder reasonableness defense is often applied - even if only implicitly - so that courts exempt doctors from liability when they prepared reasonably before exercising their judgment. Do statistics bear this out? We know of no data explicitly on point, but available data implicitly suggests a positive answer. The National Practitioner Data Bank includes 191,082 medical malpractice claims, both tried and settled, brought by patients in $1991-2005 .{ }^{18}$ The claims are arranged by category. Upon examination, these categories suggest to us that roughly eighty percent of the claims were brought for faulty execution and twenty percent were brought for misjudgments. ${ }^{19}$

\section{Products Liability}

Manufacturing inevitably results in some defective items, and quality control reduces the frequency with which defective items harm consumers. We distinguish the relevant behavior into first and second order. Roughly speaking, manufacturing the product is first-order behavior, and quality control is second-order behavior. Thus a manufacturer of a soft drink must fill bottles,

18 Public Use Data File, The DATA BANK, http://www.npdb-hipdb.hrsa.gov/resources/ publicData.jsp (last visited Dec. 18, 2013).

1937,805 claims were brought for failed diagnosis — probably more judgment than execution claims. Most of the rest were brought for various types of faulty execution. Thus 16,356 claims were brought for delay in treatment, 3286 for failed monitoring, 3943 for failed performance of a procedure, 12,275 for improper management, 28,931 for improper performance, 857 for improper use of equipment, 2054 for administering treatment on a wrong body part, 1562 for administering wrong dosage of medication, and 1913 for administering wrong medication. 
which is first-order behavior, and he also must monitor the bottles for cracks or overcharging with gas, which is second-order behavior. The more carefully the manufacturer monitors, the less often a cracked or overcharged bottle reaches consumers.

Until the second half of the twentieth century, the common law imposed a negligence rule on manufacturers for defective products that harmed consumers. To recover damages, the consumer had to prove that a defective product caused the injury and the manufacturer's negligence caused the defect. The second part of the proof usually involved showing that the manufacturer's quality control, which is second-order behavior, was unreasonable. ${ }^{20}$ Consumers seldom had enough evidence about manufacturer's quality control to meet this burden of proof. To allow more recoveries by injured consumers, American courts in the early twentieth century applied the doctrine of res ipsa. According to this doctrine, the court should infer the defendant's negligence if the specific accident belongs to a type that regularly results from negligence, and if two more conditions are satisfied..$^{21}$ The manufacturer was liable when the consumer showed that he was injured by a defective product under these conditions, unless the manufacturer could prove that its quality control satisfied the legal standard. ${ }^{22}$

The original liability rule required the plaintiff to prove second-order unreasonableness in order to recover. The rule of res ipsa allowed the defendant to escape liability by proving second-order reasonableness. Thus the change in rules reversed the burden of proof concerning second-order reasonableness. The doctrine of res ipsa was an intermediate step towards the contemporary

20 See Richard A. Epstein, Torts 386-94 (1999); James A. Henderson, Jr. \& Theodor Eisenberg, The Quiet Revolution in Products Liability: An Empirical Study of Legal Change, 37 UCLA L. REv. 479, 524 (1990) (claiming that "the growth of products liability undoubtedly has increased corporate safety consciousness"). Imperfect quality control causes a few items in a manufacturing process to fall short of the design that the others satisfy. In contrast, a defect in design affects all items manufactured according to that design. Manufacturing and design defects require a separate analysis in the law of torts. This Article discusses the former and not the latter. For a discussion of the distinction, see EPSTEIN, supra, at 406-08.

21 The other two conditions are that the event was caused by an agency or instrumentality within the exclusive control of the defendant; and that it was not due to any voluntary action or contribution on the part of the plaintiff. See Epstein, supra note 20, at 172; Ariel Porat \& Alex Stein, Tort Liability Under UNCERTAINTY 84-92 (2001).

22 Escola v. Coca Cola Bottling Co., 150 P.2d 436 (Cal. 1944); Richenbacher v. California Packing Corp., 145 N.E. 281 (Mass. 1924). 
liability rule. In the course of the twentieth century, most jurisdictions changed the rule to strict liability. This change eliminated the manufacturer's right to defend itself by showing reasonable quality control. If a product is unreasonably dangerous, the manufacturer is strictly liable for the harm the defect causes to consumers, and no amount of quality control excuses the manufacturer. ${ }^{23}$ Thus, under current law, second-order reasonableness defense does not apply anymore to defective product cases.

\section{Summary}

Given that first-order precaution is probabilistic, a crucial question for tort law is whether or not a liability rule allows a defense of second-order reasonableness. We explained that the prevailing rule of negligence in everyday accidents, such as driving, usually disallows a defense of second-order reasonableness. Likewise, the prevailing rule of strict liability for consumer injuries caused by manufacturing disallows a defense of second-order reasonableness. ${ }^{24}$ However, the prevailing rules of tort law sometimes allow a second-order defense, especially for faulty judgments by doctors, or emergency situations.

\section{Model of Lapses}

\section{A. The General Model}

The first formal model of comparative tort rules, which was published in 1973, became the standard model. ${ }^{25}$ Under all forms of the negligence rule, courts decide liability by comparing an actor's actual precaution to the legal standard. In the standard model, injurers exactly satisfy the legal standard

23 EPSTEn, supra note 20, at 389-94.

24 As we have explained, we focus on products liability for manufacturing defects. With design defects the distinction between first- and second-order negligence disappears.

25 John Prather Brown, Toward an Economic Theory of Liability, 2 J. LEGAL STUD. 323 (1973). In the standard model, no one is negligent in equilibrium (or else everyone is negligent in equilibrium), which contradicts the basic fact of tort liability: some acts are negligently performed. A small modification of the standard model allows actors, for whom precaution is idiosyncratically expensive, to choose a level of care that courts judge to be unreasonable - hence the oxymoron “intentional negligence." See Robert D. Cooter, Economic Analysis of Punitive Damages, 56 S. CAL. L. REv. 79, 89 (1983) ("If punitive damages exactly offset the injurer's illicit benefits, then his cost function will look just like that of an ordinary injurer in the zone of liability."). 
in order to escape liability. Setting the legal standard at the optimal level of care, consequently, causes actors to take optimal precaution.

The standard model did not encompass uncertainty. In many economic models, introducing uncertainty does not change individual behavior, or does not change average behavior, provided that the distribution of errors is unbiased ${ }^{26}$ and actors are risk-neutral. ${ }^{27}$ This was not the case when uncertainty was introduced into the standard model of negligence rules. ${ }^{28}$ In the standard model without uncertainty, injurers exactly satisfy the legal standard in order to escape liability. With uncertainty, injurers do not know for sure whether or not a given level of precaution that they take will enable them to escape liability. An actor's costs usually jump when his precaution falls below the legal standard of care. ${ }^{29}$ When costs are discontinuous at the legal standard,

26 An unbiased estimation of a value is equally likely to err in either direction too high or too low. Many errors are normally distributed with zero mean. The normal distribution is one form of an unbiased distribution.

27 Economists traditionally assumed that people are neutral with respect to small risks and averse to large risks. See KeNNETH J. Arrow, EsSAYs IN the Theory OF Risk-Bearing (1974). Cognitive psychology successfully challenged these assumptions by proving experimentally that the context of a decision frames the way an actor decides what to do. Cognitive psychology, or its fraternal twin, behavioral economics, improves the realism of assumptions about risk. This improvement, however, often does not change the traditional approach to modeling. Risk-averse or risk-seeking behavior differs from risk-neutral behavior in ways that are intuitive and easily modeled. So a formal theory of tort liability usually begins by assuming risk neutrality and later introduces corrections to increase the model's realism.

28 John E. Calfee \& Richard Craswell, Some Effects of Uncertainty on Compliance with Legal Standards, 70 VA. L. REv. 965 (1984) (saying that the standard model fails to explain why some acts are negligently performed).

29 The discontinuity of liability under a rule of negligence and its behavioral consequences were originally explained in Cooter, supra note 25, at 91 (claiming that "a negligence rule creates a threshold or jump in the potential injurer's costs"). Mark Grady argued against Cooter that courts would not actually hold injurers liable for more harm than they actually caused by negligently untaken precautions. See Mark F. Grady, Untaken Precautions, 18 J. LeGaL Stud. 139 (1989) ("[T]he economic modeler's claim that the negligence rule contains an incentive-distorting discontinuity crucially depends on the assumption that courts are trying to find global minima, and on the related supposition that the breachof-duty and cause in-fact issues are independent."); see also Richard Craswell \& John E. Calfee, Deterrence and Uncertain Legal Standards, 2 J.L. Econ. \& OrG. 279, 295-97 (1986) (advocating liability for incremental damages which is the difference between the social losses inflicted by injurers' activity and the social 
uncertainty causes actors to change their individual and average behavior, even when errors are unbiased and actors are risk-neutral. ${ }^{30}$ In principle, the change can result in precaution above or below the social optimum. Under reasonable assumptions, however, the change results in excessive precaution. ${ }^{31}$ Thus the standard model of negligence under uncertainty predicts that injurers will take socially inefficient precaution.

Uncertainty over liability can take various forms. One form is randomness in precautionary behavior, which makes the actor uncertain about how much precaution his efforts will realize. ${ }^{32}$ Lapses constitute a specific case of such uncertainty. We use the term "lapse" to describe the realization of too little precaution from intended effort. ${ }^{33}$ (Other forms of uncertainty, which we do not discuss, include a random element in the behavior of the court. ${ }^{34}$ ) If lapses cause most negligent injuries, as we believe, then the existing literature is thin relative to the subject's importance. A few previous papers have discussed lapses by name. ${ }^{35}$ Other authors have discussed the mathematical form of lapses while using different terminology.

To illustrate the latter, we will restate the conclusion of the standard model under uncertainty in Steven Shavell's language and in our language. Shavell defines "momentary care" as the sum of the care that the injurer can

losses that would have been inflicted had they complied with the legal standard); Marcel Kahan, On Causation and Incentives to Take Care Under the Negligence Rule, 18 J. LeGal Stud. 427 (1989). Cooter replied that the discontinuity is due to incomplete information by the courts, which is the case in fact. See Robert D. Cooter, Punitive Damages for Deterrence: When and How Much?, 40 Ala. L. Rev. 1143, 1155-57 (1989) (commenting that "[i]mperfection in the court's causal attribution may be due to the fact that some of the needed information is difficult or impossible to obtain").

30 See Calfee \& Craswell, supra note 28, at 966 ("[M] any traditional conclusions of the law-and-economics literature can no longer be defended on economic grounds .... A All of these conclusions hold even when defendants are riskneutral.").

31 Id.; Steven Shaveld, Economic Analysis of Accident Law 81-83 (1987).

32 ShAVELL, supra note 31.

33 Supra Introduction (first paragraph).

34 For instance, the injurer may be uncertain about the standard of care that the court will apply to his behavior, or uncertain about the actual level of care that the court will find that he has taken.

35 Robert D. Cooter, Lapses, Conflict, and Akrasia in Torts and Crimes: Towards an Economic Theory of the Will, 11 InT'L Rev. L. \& ECon. 149 (1991); Mark F. Grady, Why Are People Negligent? Technology, Nondurable Precautions, and the Medical Malpractice Explosion, 82 Nw. U. L. REv. 293 (1988); Grady, supra note 29. 
control and a random variable. The random variable prevents full control of momentary care. ${ }^{36}$ Similarly, in our model of lapses, randomness infects first-order precaution, and the injurer controls his second-order precaution. Second-order precaution and a random error determine first-order precaution. Thus Shavell's "momentary care" corresponds to our "first-order precaution," and Shavell's "controlled care" corresponds to our "second-order precaution." A failure to meet the "momentary care" legal standard is a "lapse" in our terminology.

At a minimum, random errors often infect first-order precaution more than second-order precaution. Thus drivers choose their intended speed and imprecisely control their actual speed; manufacturers choose their rate of product sampling and unintentionally diverge from the intended sampling rate; and corporate directors prepare to decide and imprecisely control the consequences of their decisions. To study such cases, we retain the standard assumption that random errors infect first-order precaution and not second-order precaution. (Modeling higher-order randomness is possible but undesirable for our purposes..$^{37}$ )

In Shavell's model, courts focus on the instant of the injury when deciding liability. Courts thus hold the injurer liable for harm caused by momentary care that falls short of the legal standard, regardless of the injurer's level of controlled care. Similarly, in our model, the standard negligence rule holds the injurer liable for harm caused by his first-order negligence, without allowing a defense of second-order reasonableness. Under the standard liability rule, the injurer generally has incentives to take more or less controlled care than the socially efficient level. ${ }^{38}$

We use some notation and two graphs to clarify these arguments. $x_{1}$ indicates first-order precaution, which is a random variable. $x_{2}$ indicates second-order precaution (e.g., preparation and self-monitoring). $\mathrm{p}\left(\mathrm{x}_{1} \mid \mathrm{x}_{2}\right)$ indicates the probability density function for first-order precaution, conditional

36 SHAVELL, supra note 31 , at 81-83, 94-96.

37 To model second-order errors, we could assume that third-order precaution and a random variable determine second-order precaution. And we can keep going to higher orders. Higher orders of lapses are relevant to studying irresolute intentions of drivers, the failure of quality control workers to sample at the rate prescribed by management, and accidental failure of corporate directors to obtain information that they sought for making a decision.

38 ShavelL, supra note 31 , at $81-83,93-96$. Shavell also rightly pointed out that momentary level of care is an imperfect indicator of the true, but unobservable, level of care and wondered whether courts might sometimes lower the level of due care in implicit recognition of the injurers' problem in controlling their momentary level of care. Id. at 81-82. 
on second-order precaution. Figure 1 depicts the probability of realizing particular values of first-order precaution. In Figure 1, the actor's particular value of second-order precaution $\mathrm{x}_{2}$ equals $\tilde{a}$.

\section{Figure 1: Probability of a Negligent Lapse}

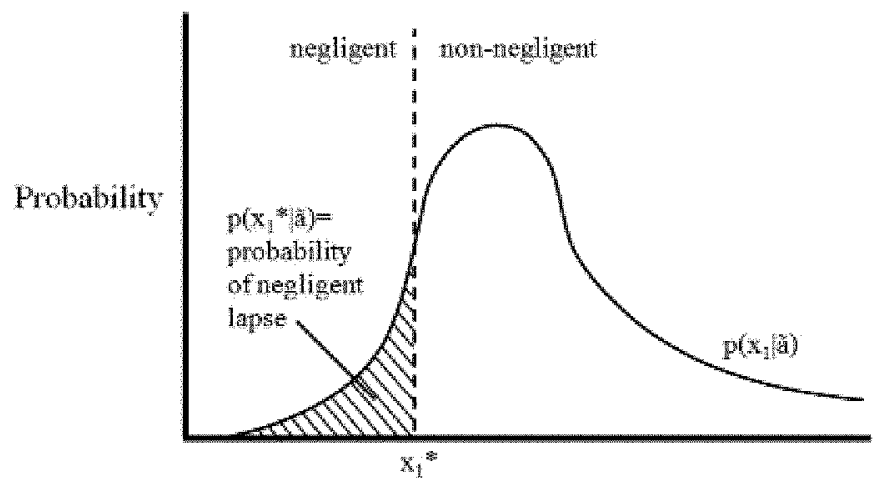

Ist Order Beltanot $\mathrm{x}_{1}$

More second-order precaution $\mathrm{x}_{2}$ will reduce the probability of a lapse, as indicated by a change in the probability density function. The increase in second-order precaution may increase the mean of first-order precaution as when a driver aims for a lower average speed, or reduce its variance as when a driver checks the speedometer more often. Figure 2 depicts a change in mean and variance caused by an increase in $\mathrm{x}_{2}$ from the relatively low value denoted ã in Figure 1 to the relatively high value denoted â in Figure 2.

\section{Figure 2: Shift in Probability of a Negligent Lapse}

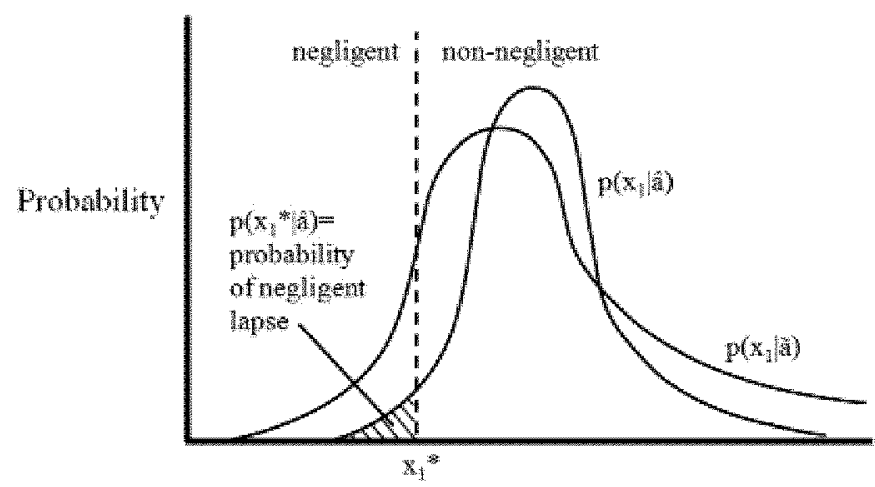

lst Order Behwior $x_{1}$ 
$\mathrm{x}_{1}$ * indicates the legal standard for precaution $\mathrm{x}_{1}$, which is the same in Figure 1 and Figure 2. The vertical line at $x_{1}{ }^{*}$ partitions the figures into negligent and non-negligent zones. If an accident occurs when $\mathrm{x}_{1}<\mathrm{x}_{1}{ }^{*}$, and the accident would not have occurred if $x_{1} \geq x_{1}^{*}$, then the actor's negligent lapse caused the accident. The standard negligence rule holds the actor liable for harms caused by negligent lapses. The shaded area in Figure 1 depicts the probability of first-order negligence, which equals the cumulative probability: $\mathrm{P}\left(\mathrm{x}_{1}{ }^{*} \mid \tilde{\mathrm{a}}\right)={ }_{0}{ }^{\mathrm{x}{ }^{*}} \mathrm{p}\left(x_{1} \mid \tilde{\mathrm{a}}\right) \mathrm{d} x_{1}$. An injurer who takes second-order precaution $\tilde{\mathrm{a}}$ will lapse with a probability of $\mathrm{P}\left(\mathrm{x}_{1}{ }^{*} \mid \tilde{\mathrm{a}}\right)$, and not lapse with a probability of $1-P\left(x_{1}^{*} \mid \tilde{a}\right)$. The decrease in size of the shaded area in Figure 2 as compared to Figure 1 indicates a fall in the probability of a lapse due to an increase in second-order precaution.

By definition, the socially optimal level of second-order precaution, which we denote $\mathrm{x}_{2}{ }^{*}$, minimizes the sum of the cost of accidents and the cost of precaution. In the standard model of negligence under uncertainty, as mentioned above, the possibility of lapses can result in excessive or deficient precaution relative to the social optimum..$^{39}$ To illustrate, assume that the socially optimal level of second-order precaution equals the level of precaution ã that generates the probability distribution in Figure 1. The prevailing liability rule, however, might induce the injurer to take second-order precaution equal to â that generates the probability distribution in Figure 2. Under these assumptions, the socially optimal distribution of accidents in Figure 1 differs from the distribution in Figure 2 that minimizes the injurer's private costs.

The standard model of negligence under uncertainty omits significant institutions that affect particular types of precaution. To illustrate, Jennifer Arlen and W. Bentley MacCloud make a major advance by explicitly incorporating insurance and healthcare organizations into a model of medical malpractice with two orders of precaution. ${ }^{40}$ We extend the standard model in a different

39 ShavelL, supra note 31, at 80-83; Calfee \& Craswell, supra note 28.

40 In a component of this expansive model, an individual physician has to make a decision. The probability that the physician knows which decision is the right one depends on information, which in turn depends on the physician's "expertise." Besides expertise, the probability of a right decision also depends on luck. So "expertise" in this model looks like a form of second-order precaution, and the physician's wrong decision looks like a form of first-order negligence. The authors conclude that holding physicians liable for the harm caused by bad decisions provides socially efficient incentives, provided that courts set damages according to a novel formula that they specify. Jennifer Arlen \& W. Bentley MacLeod, Malpractice Liability for Physicians and Managed Care Organizations, 78 N.Y.U. L. REv. 1929 (2003) [hereinafter Arlen \& MacLeod, Malpractice Liability]; Jennifer Arlen \& W. Bentley MacLeod, Torts, Expertise, 
direction by analyzing the information effects of a liability rule that recognizes a defense of second-order reasonableness.

Recall that a first-order negligence rule assigns liability for harm as follows: $\mathrm{x}_{1}<\mathrm{x}_{1}{ }^{*}=>$ injurer is liable.

$x_{1} \geq x_{1}^{*}=>$ injurer is not liable.

Similarly, applying a standard of negligence to second-order behavior has this form:

$\mathrm{x}_{2}<\mathrm{x}_{2}{ }^{*}=>$ injurer is liable.

$\mathrm{x}_{2} \geq \mathrm{x}_{2}^{*}=>$ injurer is not liable.

A liability rule recognizes a defense of second-order reasonableness when: $\mathrm{x}_{1}<\mathrm{x}_{1}^{*} \& \mathrm{x}_{2} \geq \mathrm{x}_{2}^{*}=>$ injurer is not liable.

The injurer is not liable when $\mathrm{x}_{1}$ falls below the legal standard $\mathrm{x}_{1}{ }^{*}$ and $\mathrm{x}_{2}$ equals or exceeds the legal standard $x_{2}{ }^{*}$.

\section{B. Introducing a Second-Order Reasonableness Defense}

In Shavell's model, courts can observe momentary precaution and they cannot observe controlled care, so courts base liability solely on the former and not on the latter. In reality, however, the liability rule affects what the courts can and cannot observe. A liability rule that allows a defense of second-order reasonableness encourages potential injurers to make their second-order precaution observable. Jennifer Arlen and Reinier Kraakman have made a similar argument concerning the vicarious liability of the corporation. ${ }^{41} \mathrm{We}$ extend the standard model of negligence under uncertainty by allowing the injurer to make an additional choice besides second-order precaution. In addition, the injurer in our model controls the court's ability to observe his second-order precaution.

and Authority: Liability of Physicians and Managed Care Organizations, 36 RAND J. Econ. 494 (2005) [hereinafter Arlen \& MacLeod, Torts, Expertise, and Authority].

41 They contrast a rule of strict vicarious liability and a negligence rule for harm caused by the employees of a corporation. They argue that strict vicarious liability discourages corporations from detecting and reporting misconduct by firm's agents after the fact, whereas a negligence rule encourages the corporation to gather this information. See Jennifer Arlen \& Reinier Kraakman, Controlling Corporate Misconduct: An Analysis of Corporate Liability Regimes, 72 N.Y.U. L. REv. 687 (1997). 
Specifically, the injurer can spend $\mathrm{k}$ before the accident occurs, which will make his precaution $\mathrm{x}_{2}$ observable by the court. For example, a doctor can perform tests before deciding to operate on a patient and then provide the test data to the court; or a driver can record his speed and then provide the record to the court; or a CEO can document his diligence before selling a corporate opportunity and then provide the documents to the court. Without expenditure $\mathrm{k}$, precaution $\mathrm{x}_{2}$ is not observable by the court.

Different liability rules give different incentives for the injurer to make his precaution observable to the court. Consider the rule that dominates prevailing tort law: a rule of liability for first-order negligence with no second-order defense. The injurer's second-order behavior is irrelevant to liability, so he has no legal incentive to make it observable. Furthermore, in the standard model, the injurer takes socially inefficient precaution.

Next, consider a liability rule requiring the plaintiff to prove first- and secondorder negligence. The plaintiff must prove both that $\mathrm{x}_{1}<\mathrm{x}_{1}{ }^{*}$ and that $\mathrm{x}_{2}<\mathrm{x}_{2}{ }^{*}$ in order to recover damages. This rule prevailed in the early twentieth century in product liability cases. To recover under this rule, the consumer must prove that he was injured by a defective product $\left(\mathrm{x}_{1}<\mathrm{x}_{1}{ }^{*}\right)$ and the manufacturer's negligence $\left(\mathrm{x}_{2}<\mathrm{x}_{2}{ }^{*}\right)$ caused the defect. ${ }^{42}$ If $\mathrm{x}_{2}$ is unobservable, the plaintiff cannot prove $\mathrm{x}_{2}<\mathrm{x}_{2}^{*}$, so the injurer escapes liability, regardless of whether his second-order precaution is reasonable or unreasonable. Consequently, the injurer has no incentive to make his second-order precaution observable. Tort law provides no incentive for the injurer, having escaped liability, to take reasonable precaution.

Finally, consider a negligence rule with a defense of second-order reasonableness. If the plaintiff proves that $\mathrm{x}_{1}<\mathrm{x}_{1}{ }^{*}$, then the defendant must prove that $\mathrm{x}_{2} \geq \mathrm{x}_{2}$ * in order to avoid liability. This rule exists in a limited way in some areas of law, as shown in Part I. The injurer can escape liability by making his second-order precaution observable, provided it is reasonable. If cost $\mathrm{k}$ is not too high, the injurer will take reasonable second-order precaution and make it observable to the court as a defense against liability ${ }^{43}$ Thus a rule of first-order negligence with a defense of second-order reasonableness will

\section{Supra Section I.C.}

43 Note that if law allows a defense of second-order reasonableness, then actors will tend to favor activities where second-order precaution is easier for courts to observe. Thus courts should especially allow a defense of second-order reasonableness when it wants to favor an activity with observable second-order precaution and to disfavor a substitute activity with unobservable second-order precaution. The court should favor one activity over a close substitute when the former has positive externalities. See infra Part III. 
often cause injurers to satisfy the legal standard for second-order precaution and make this fact observable. ${ }^{44}$

We summarize these arguments:

Proposition. Assume that the injurer controls second-order precaution $\mathrm{x}_{2}$, and the injurer's first-order precaution $\mathrm{x}_{1}$ is a function of $\mathrm{x}_{2}$ and a random error term. The injurer can spend $\mathrm{k}$ to make $\mathrm{x}_{2}$ observable to the court; otherwise it is unobservable.

- Under a negligence rule without a second-order defense, $x_{2}$ will be unobservable to the court and socially inefficient.

- Under a rule requiring the plaintiff to prove first- and second-order negligence, $x_{2}$ will be unobservable to the court and socially deficient.

- Under a first-order negligence rule with a second-order defense, $x_{2}$ will be observable to the court and equal to the legal standard, provided that $\mathrm{k}$ is not too large. Assuming the legal standard is set at the efficient level, $\mathrm{x}_{2}$ will be socially efficient.

This proposition grounds our policy recommendation: make a defense of second-order reasonableness available more generally. The defense is an "information-forcing mechanism." It is useful whenever courts need to induce injurers to reveal their second-order behavior in order to improve incentives for precaution. ${ }^{45}$ The next two Parts explain that the defense is also useful

44 This conclusion resembles the proposition that a rule of strict liability discourages corporations from reporting harms that they cause, whereas a rule of negligence encourages them to report cases where the corporation has a defense of reasonable precaution. See Arlen \& Kraakman, supra note 41. Note that the second-order reasonableness defense applies to lapses, not to intentional fault. Distinguishing between them can be difficult, as an example illustrates. (We are grateful to Mark Geistfeld for this example.) Suppose that the driver of a car swerves and hits a parked car. The driver contends that his foot accidentally slipped on the gas pedal, so the accident resulted from a lapse. The plaintiff contends that the driver swerved because he reached for a cassette on the floor, so the accident resulted from intentional fault. If the liability rule permits a defense of secondorder reasonableness for lapses, it applies to the first possibility and not to the second. Before determining whether the defendant can offer a defense of secondorder reasonableness, the court will have to decide whether the accident's cause was a lapse or intentional fault. This decision may be easy or hard, but it is no different in kind from many other factual questions that courts must resolve.

45 Arlen and MacLeod do not favor defense of second-order unreasonableness. Such a defense is unnecessary in their model because courts do not need to use it to force injurers to reveal information about second-order precaution. So the Arlen and MacLeon model applies to a world where second-order precaution is observable, and our model applies to a world where it is revealable. See Arlen 
when the underlying activity has positive externalities, or when expanding the defense causes injurers to substitute less dangerous activities for more dangerous ones.

\section{Negative and Positive Externalities}

Under a negligence rule, the actor escapes liability whenever his behavior satisfies the legal standard of precaution. When the actor escapes liability, the harm from the accident is not the actor's private cost, although it is a social cost of engaging in the activity. The standard model implies that a negligence rule causes too much activity with negative externalities. ${ }^{46}$

The opposite is true for activities with external benefits. Under a negligence rule, the actor is liable for the harm that he causes whenever he lapses. However, the external benefits of his activity accrue to others, not to himself. The standard model implies that a negligence rule causes too little activity with positive externalities. A simple example of an activity with positive externalities is volunteering to work for nonprofit organizations. By definition, volunteers benefit others without being paid. The standard model implies that a negligence rule applied to harm caused by volunteers would cause too little volunteering. A far more complicated example of positive externalities is practicing medicine. Although the institutional framework differs from place to place, doctors apparently get paid less than the benefits that their services convey to their patients. ${ }^{47}$ Doctors also create benefits to third parties who

\& MacLeod, Malpractice Liability, supra note 40; Arlen \& MacLeod, Torts, Expertise, and Authority, supra note 40.

46 SHAVELL, supra note 31, at 21-32.

47 See David S. Bloch \& William R. Nelson, Jr., Defining 'Health': Three Visions and Their Ramifications, 1 DePaul J. Health Care L. 723, 731 (1997) ("Commentators who consider health a non-marketable good contend that there are elements of health which, though valuable, are unquantifiable, such as hope, compassion, and the extension and preservation of life .... Health's social benefits are not fully realized by the market price it commands."); T.R. Marmor, Richard Boyer \& Julie Greenberg, Medical Care and Procompetitive Reform, 34 VAND. L. REv. 1003 (1981) ("Improved health, the anticipated outcome of medical care, has positive externalities. This makes medical care a merit good, and, unlike many other economic goods, one that should not be allocated solely on the basis of ability to pay."); Stuart Rome, Medicine and Public Policy: Let Us Look Before We Leap Again, 41 MD. L. Rev. 46 (1981); see also Maja Campbell-Eaton, Antitrust and Certificate of Need: A Doubtful Prognosis, 69 Iowa L. REv. 1451 (1984) ("Moreover, health care usually is viewed as a 'merit good,' with benefits extending beyond its economic value. This view is reinforced by the ethical 
do not pay for them. ${ }^{48}$ The standard model implies that a negligence rule will cause too little doctoring in many institutional settings.

The two types of externalities - negative and positive - provide a reason for disallowing or allowing a defense of second-order reasonableness. When external effects are harmful, a negligence rule tends to cause socially excessive activity. A defense of second-order negligence aggravates the problem by allowing some injurers to escape the social costs of their lapses. So a liability rule that allows a defense of second-order reasonableness worsens incentives to engage in activities with external costs, such as driving. ${ }^{49}$ Conversely, when external effects are beneficial, a negligence rule tends to cause socially deficient activity. A defense of second-order negligence ameliorates the problem by allowing some injurers to escape the harm caused by their lapses. So a liability rule that allows a defense of second-order reasonableness improves

mandates of the health professions and by a widespread belief that 'more is better' in the provision of medical services."). On the inability of doctors to pass higher insurance costs along to patients, see Peter Eisler, Julie Appleby \& Martin Kasindorf, Hype Outraces Facts in Malpractice Debate, USA TODAY, May 3, 2003, http://www.usatoday.com/news/nation/2003-03-04-malpractice-cover_x. $\mathrm{htm}$ (claiming that the cause of this inability is the limitations on reimbursements made by managed care insurers, Medicare and Medicaid).

48 See also Robert D. Cooter \& Ariel Porat, Liability Externalities and Mandatory Choices: Should Doctors Pay Less?, 1 J. Tort L., Dec. 2006, Art. 2, http:// www.degruyter.com/view/j/jt1.2006.1.1/jt1.2006.1.1.1040/jt1.2006.1.1.1040. $\mathrm{xml}$ ?format=INT (by subscription). We endorse the view that positive externalities exceed the negative externalities. See id. For the argument that medical practice has negative externalities due to the fact that many patients who sustained injury as a result of negligence do not sue, see Tom Baker, The Medical Malpractice Мүтн (2005). For the argument that many patients do not bring suits and for the reasons for that, see Hyman \& Silver, supra note 15.

49 Introducing the defense of second-order reasonableness reduces the expected cost of engaging in the activity while taking reasonable precaution. Consequently, more people engage in the activity, they have more lapses, and the lapses cause more injuries. So removing the defense improves incentives with respect to activity level. Incentives may not improve with respect to second-order precaution. Most actors satisfy the legal standard of second-order precaution in order to have a defense against liability. Appropriate choice of the legal standard for second-order precaution $\mathrm{x}_{2}{ }^{*}$, consequently, can induce socially optimal secondorder behavior in spite of external costs. In our model, second order behavior is the only way to affect the probability distribution over first-order behavior, so optimal second-order behavior necessarily achieves the optimal distribution over first-order behavior. 
incentives to engage in activities with external benefits, such as volunteering and doctoring.

\section{Substitution}

Having discussed positive externalities, we turn to another justification for having a defense of second-order reasonableness. Some activities and some forms of precaution are more susceptible to lapses than others. A rule imposing liability for lapses creates an incentive to switch to activities and forms of precaution that are less susceptible to lapses. The switch creates a problem when the activities and forms of precaution that are less susceptible to lapses are also inherently more dangerous.

We will illustrate this point numerically by comparing social and private costs under two forms of precaution, as summarized in Table 1. Assume that performing an activity without any precaution causes accidental harm of 500. Precaution A costs 100 and reduces accidental harm from 500 to 300. With Precaution A, the total social costs equal 400, which is the sum of accidental harm (300) and precaution (100). Alternatively, Precaution B costs 120 and reduces accidental harm from 500 to 350 . With Precaution B, the total social costs equal 470, which is the sum of accidental harm (350) and precaution (120). With these numbers, Precaution A has a lower social cost than Precaution B.

Table 1

Precaution costs Accidental harm Total social costs

\begin{tabular}{lrrr}
\hline No precaution & 0 & 500 & 500 \\
\hline Precaution A & 100 & 300 & 400 \\
\hline Precaution B & 120 & 350 & 470 \\
\hline
\end{tabular}

Now we consider the private costs of the injurer under the standard negligence rule. After taking Precaution A, the remaining harm from accidents is 300 . Assume that this harm is due to lapses by the injurer, so the injurer is liable for 300 under the standard negligence rule. Consequently, the injurer's private costs under Precaution A equal 400, which is the sum of liability (300) and precaution (100). Alternatively, after taking Precaution $\mathrm{B}$, the remaining harm from accidents is 350 . Assume that this harm is due to nature, not the injurer's lapses, so the injurer is not liable under the standard negligence rule. Consequently, the injurer's private costs under Precaution B equal 120 , which is the sum of liability (0) and precaution (120). 
In this numerical example, social costs are lower with Precaution A than with Precaution B, but the injurer's private costs under the standard negligence rule are lower with Precaution B than with Precaution A. Thus the standard negligence rule gives the actor an incentive to choose Precaution B instead of Precaution A, thus substituting the socially inefficient precaution for the socially efficient precaution. The standard negligence rule creates perverse incentives in this example because the natural risks from Precaution B exceed the risk of lapses from Precaution A.

Allowing a defense of second-order reasonableness would reverse the incentives. Assume that Precaution A is a reasonable second-order precaution. Thus the actor who chooses Precaution A has a defense against liability for lapses. ${ }^{50}$ Now the actor's private costs equal 100 under Precaution A and 120 under Precaution B, so the actor will choose the socially efficient precaution. ${ }^{51}$ The law should encourage actors to use the forms of precaution that are socially more efficient. To do so, liability law should encourage the forms of precaution that are inherently less dangerous. Doing so sometimes requires liability law to allow a defense of second-order reasonableness.

The preceding examples concern two forms of precaution. Previous authors have discussed incentives under "several dimensions of care." When two measures could be taken to reduce the expected harm, the question is how to incentivize the injurer to take the optimal combination of them. As Shavell indicated, under a negligence rule an injurer would have a motive to choose optimal levels "only to those dimensions of care that are incorporated in the due care standard. . . . Some dimensions of care will usually be omitted from the due care standard because of difficulties that courts would face in ascertaining them ... or in determining proper behavior in respect to them." ${ }_{52}$ The substitution effect that we analyze in this Article is also a result of courts' failure to incorporate an important dimension into the standard of care: the second-order behavior of the injurer.

The substitution effect is not unique to lapses. Whenever liability law allows an actor to externalize part of the costs and benefits of his actions, there is a risk that the law will incentivize him to choose the more socially

50 Alternatively, a court could hold that Precaution A is reasonable because it is socially efficient, and Precaution B is unreasonable because it is socially inefficient. Equating "reasonable" with "efficient" requires that courts have a lot of information on untaken precautions.

51 The other way to restore efficient incentives, which we do not discuss here, is to impose strict liability for any harm resulting from the activity.

52 Steven Shavell, Foundations of Economic Analysis of Law 182 (2004). 
costly alternative..$^{53}$ This Article has shown that a defense of second-order reasonableness should be available when it prevents actors from switching to less effective forms of precaution. Next we discuss some concrete examples.

\section{A. Capital vs. Labor}

The following example illustrates that an actor can sometimes reduce liability under the standard negligence rule by performing a task with a machine instead of a person, even though the machine is less efficient.

Example 2: Traffic Light and Policeman. The municipality must decide whether to post a policeman in the intersection to direct traffic or to install a traffic light. A policeman is more flexible than the traffic light, so traffic flows more quickly. However, a policeman is more susceptible to lapses than traffic lights are susceptible to failures that cause accidents.

If the social benefits of flexibility exceed the cost of lapses, the policeman may be more efficient. However, the standard negligence rule creates an incentive for the municipality to replace a policeman with a traffic light. The machine does not lapse. Even if traffic lights occasionally fail to operate properly, the municipality can argue in court that it used the best available technology, so it was not at fault.

The choice between labor and capital, or manpower and machines, often occurs in settings involving accidents. Employers must decide whether to reduce risks to employees in the workplace by using safer machines or by imposing safer work rules on employees. Hospitals and other providers of medical services must decide whether to monitor their patients' condition by sophisticated equipment or by their medical stuff. Airport authorities and airlines must decide whether to promote passengers' safety by new technologies or by posting guards. Lastly, drivers must decide whether to rely on devices like cruise controls or human skills. Technology is sometimes more effective than manpower in avoiding accidents, and sometimes the opposite is true. Courts, however, are more likely to find fault when humans lapse than when

53 Here are some causes of the substitution effect: First, sometimes one form of precaution is harder to verify in court than another. Second, under a negligence rule, the extent of the unavoidable losses for which the actor is not liable may differ for each form of precaution. Third, one choice sometimes creates positive externalities that are higher than those created by the other choice. See Cooter \& Porat, supra note 48. 
machines fail that are reasonably maintained. This fact biases the choice against humans and in favor of machines. ${ }^{54}$

\section{B. Susceptibility of Human Precautions to Lapses}

A second form of substitution is between human precautions that differ in their susceptibility to lapses, as illustrated by Example 3 .

Example 3: Deliveries of Babies. Doctors must decide between vaginal and caesarean delivery of a baby. Assume courts cannot verify ex post whether the doctor's decision was right or wrong, so no liability attaches to the doctor's decision to deliver by caesarean, even when the decision was bad. Courts, however, can verify whether the doctor lapsed in executing the delivery, and also whether that lapse caused the injury. ${ }^{55}$ Assume that doctors are more likely to lapse in executing a vaginal delivery than in executing a caesarean delivery. Also assume that caesarean delivery is inherently more dangerous in the long run than vaginal delivery.

In Example 3, the prevailing negligence rule gives doctors an incentive to perform too many caesarean deliveries. ${ }^{56}$ To illustrate numerically, assume that vaginal delivery harms the mother $1 \%$ of the time, and a lapse by the doctor is the cause in $75 \%$ of these cases. Thus vaginal delivery results in doctor's liability to the injured mother in $0.75 \%$ of cases. By contrast, assume that caesarean delivery harms the mother $2 \%$ of the time and a lapse by the doctor is the cause in $25 \%$ of these cases. Thus caesarean birth results in doctor's liability to the injured mother in $0.50 \%$ of cases. According to these numbers, and assuming for the sake of simplicity that materialized harm in a case of an accident is the same in both procedures, a first-order negligence rule makes the accident risk for mothers twice as great from caesarean birth as from vaginal birth, whereas the liability risk for doctors is half as great from caesarean birth as from vaginal birth. ${ }^{57}$

54 Interesting, Grady, supra note 35, argued that new technologies result in higher standards of liability, so tort liability obstructs innovation and development. Our argument points to an opposite influence.

55 The distortions caused by tort law with respect to caesarean and vaginal birth are extensively analyzed by this Article's authors in Cooter \& Porat, supra note 48.

56 We assume that doctors cannot adjust their prices to account perfectly for the different liability risks of liability posed by each procedure.

57 In general, doctors are advised by risk management experts to choose procedures that reduce their liability potential, when the enhanced risk is not captured by 
Substituting machines for people, in Example 2, and substituting human precaution less susceptible to lapses for human precaution more susceptible to lapses, in Example 3, reduced liability under the standard negligence rule. Similarly, substituting bureaucratic rules for human discretion can reduce an organization's liability under the standard negligence rule, as we illustrate.

Example 4. Regulation vs. Discretion. The police department is considering how to regulate policemen in various circumstances. One alternative is to regulate policemen's behavior by a comprehensive set of specific rules. The police can apply these rules mechanically with few lapses. However, comprehensive rules make the police inflexible and ineffective. Second, the police department can provide police with general principles. The application of general principles often results in lapses in judgment. However, general principles make the police more flexible and effective.

What will the police department do under the prevailing rule of negligence? It may wish to decrease its liability risks at the cost of decreasing its effectiveness by imposing specific rules that eliminate discretionary judgment. In general, an organization that imposes strict rules on employees who engage in risky activities may reduce its liability by reducing the frequency of lapses, even though the elimination of employees' discretion increases the total risk to the public.

\section{Execution vs. Judgment}

Earlier we discussed the difference between deciding what to do and executing the decision that you made. We noted examples where courts allow actors to escape liability for bad decisions but not for faulty executions. When courts impose liability for faulty executions but not for faulty decisions, actors have an incentive to choose the precautions least susceptible to lapses in execution and more susceptible to lapses in judgment, even when the latter are less efficient than the former. Example 5 illustrates such a case.

prices. See Charles F. Fenton \& David Edward Marcinko, Risk Management in Modern Medical Practice, in Insurance and Risk Management Strategies, supra note 12, at 107, 133:

[Physicians] should evaluate their own practice and identify those procedures and those patient types that carry a high risk of malpractice for which the physician is not adequately reimbursed. Physicians then should tailor their practice so that they no longer provide those services. The revenue lost will be worth the risk of the malpractice suit and the collateral consequences. 
Example 5. Treating Cancer. Hospital X must adopt Treatment A or Treatment B for a patient's cancer. Treatment A involves a particular procedure that is difficult to execute. Treatment B involves difficult choices among procedures that are easy to execute. If courts are quick to find fault in the execution of a procedure, then Treatment A causes relatively high risk of liability for the hospital. If courts are reluctant to "second guess" the hospital's decisions, then Treatment B causes relatively low risk of liability. If the hospital cannot perfectly adjust prices for each treatment to reflect liability risks, the standard negligence rule may cause the hospital to prefer Treatment B. However, Treatment $\mathrm{B}$ may be inherently more dangerous.

\section{Implementing Second-Order Defenses}

Now we turn to a doctrinal problem with a defense of second-order reasonableness. (We leave some other issues for future research. ${ }^{58}$ ) In our model, an increase from unreasonable to reasonable second-order precaution

58 Here are two. The first issue relates to the alternatives for reducing risks: should a defendant who failed to take reasonable second-order precautions be allowed to show that at an earlier stage he took second-order precautions beyond the ones required by reasonableness, and in general reduced risks significantly? To illustrate, should a driver who lapsed and caused an accident be allowed to raise the argument that he installed in his car expensive safety devices which he was not obliged to install, thereby reducing risks dramatically, although given the existence of the devices his second-order behavior was unreasonable?

The second issue relates to third parties' second-order behavior: should a doctor who lapsed due to fatigue and caused injury be allowed to show that the hospital required him to work too many extra hours? If such a defense is allowed for the doctor, it will be essential to impose liability on the hospital, conditioned upon establishing its negligence. $C f$. Mello \& Studdert, supra note 12 (arguing that instead of focusing on individual doctors' negligence, tort law should focus on institutions, and impose enterprise liability; and that systemic errors are major causes of most medical accidents even if typically combined with individual errors). The authors also suggest that "most promising opportunities for injury prevention lie at the organizational level," id. at 601, and that "system factors may underlie many physician errors in the sense that they create conditions in which human error is likely to occur and to go unnoticed until injury results," $i d$. at 609 . An analogous question relates to gatekeepers' liability: under what conditions it is desirable to impose liability on gatekeepers in addition to, or instead of, the direct cause of the injury. This general question is beyond the scope of this Article. See Doug Lichtman \& Eric Posner, Holding Internet 
decreases the probability of an accident. However, the probability of an accident does not fall all the way to zero. We believe that these features of our model, which reflect reality for most accidents, create a dilemma for courts. In standard tort doctrine, unreasonable behavior is the cause of an accident if it is more likely than not that reasonable behavior in the circumstances would have prevented the accident. If courts apply this doctrine literally to second-order behavior, the plaintiff will rarely satisfy the standard of proof necessary to establish causation, and second-order negligent defendants will seldom be found liable.

To see why, assume that the plaintiff can convince the court that reasonable second-order precaution by the defendant would have reduced the probability of an accident caused by a lapse. Even so, it might be difficult to convince the court that it is more likely than not that if the defendant had taken reasonable second-order precaution the specific accident would have been prevented. Specifically, assume that a driver's second-order negligence increased the probability of a lapse causing an accident from three percent to four percent. In this specific case the lapse materialized and caused an accident. The injurer would argue in court that it is more likely than not that the same accident would have occurred in this specific case even if he had taken reasonable second-order precaution.

We have no general solution to this problem for second-order negligence, but we mention the consequences of some alternatives. A court might feel compelled by the prevailing causation doctrine to find "no liability" whenever the probability is fifty percent or less that reasonable second-order precaution would have prevented the accident. In that case, the court gives injurers deficient incentive to take second-order precautions in the usual circumstances. At the opposite pole, the court might presume that the defendant caused an accident whenever his second-order unreasonableness increased its probability. This solution is a practical one and relatively easy to implement, and it certainly constitutes an improvement on the current rule under which a second-order reasonableness defense is not allowed.

We can imagine intermediate rules in between these polar types. First, a principle of probabilistic recovery can apply to lapses. Under this solution, the driver whose second-order negligence increased the probability from three percent to four percent of a lapse causing an accident would compensate the

Service Providers Accountable, 14 Sup. Cт. Econ. Rev. 221 (2006) (arguing for imposing liability on internet service providers). 
victim for twenty-five percent of her harm. ${ }^{59}$ Probabilistic recovery raises many issues that we cannot discuss here. ${ }^{60}$

Alternatively, a rule of liability for excessive harm can be applied for repeat harms. Assume that an actor caused $n$ units of harm over a certain period of time, while only $m$ units of harm would have been produced if the actor had behaved reasonably. Thus " $n$ " might refer to the actual annual harm in a hospital, and " $m$ " might refer to the annual harm that reasonable precaution would have caused. By the rule of liability for excessive harm, the hospital is liable for the excessive harm, which is $n-m$. (Elsewhere we have analyzed the rule of liability for excessive harm, which economizes on information needed by courts. ${ }^{.1}$ )

\section{Conclusion}

Lapses cause a high proportion of accidents, but they are under-theorized in liability law. To model lapses, we assume that actors draw precaution from a probability distribution. We call the result of this draw "first-order precaution" because it determines the probability of an accident. A lapse is a draw from the distribution's lower tail. Under the prevailing tort rule, the injurer is liable for harm caused by a lapse that falls below the standard of reasonable care. "Second-order precaution" refers to behavior that changes the probability distribution for first-order precaution. Preparation and self-monitoring are two general forms of second-order behavior. More second-order precaution decreases the probability of lapsing, which decreases the probability of an accident. Thus first-order precaution directly reduces the probability of an accident, whereas second-order precaution indirectly reduces the probability of an accident.

59 In one out of four cases the lapse which caused the accident was caused by the second-order negligence. The probability that the lapse in question is the one caused by the second-order negligence is therefore a quarter.

60 See Porat \& Stein, supra note 21, at 101-29.

61 Robert D. Cooter \& Ariel Porat, Total Liability for Excessive Harm, 36 J. LEGAL STUD. 63 (2007). Applying this rule requires information on aggregate harm, both actual $n$ and ideal $m$. However, applying this rule does not require information on individual harms. Avoiding proof on a case-by-case basis greatly reduces the information requirements for liability law. Notice that the optimal units of harm $m$ are the amount resulting from a reasonable level of second-order precaution. So liability for excessive harm can be viewed as a variant of the rule of secondorder negligence. 
Under the prevailing tort rule, an actor is usually liable for the harm caused by a lapse, regardless of how much precaution he takes to avoid lapsing. The prevailing tort rule makes sense most of the time because courts usually cannot verify the reasonableness of second-order behavior. It is hard to prove that a driver's self-monitoring was reasonable or unreasonable, or that a doctor made reasonable or unreasonable preparation for an operation, or that a policeman who lapsed in directing traffic does so less or more often than a reasonable policeman. However, liability law sometimes permits a defense of second-order reasonableness. Thus courts are reluctant to second-guess decisions made in emergencies or judgments by doctors who balance various considerations. In these cases, an actor can often escape liability for a defective judgment by showing that he took reasonable preparations to make it.

We advocate making the defense of second-order reasonableness available more generally. The defendant should bear the burden of proving that his secondorder behavior was reasonable, rather than the plaintiff bearing the burden of proving that the defendant's second-order behavior was unreasonable. The burden of proof should fall on the defendant because he is better situated than the plaintiff to provide evidence on his second-order behavior. A second-order reasonableness defense provides incentives for potential injurers to satisfy the standard of second-order precaution and to make this fact observable to courts. Thus cautious drivers may install recording devices to prove that they seldom speed, doctors may document preparations for an operation, and police departments may track accidents caused by officers.

Modifying the prevailing tort rule to allow a defense of second-order reasonableness has three distinct advantages over the prevailing negligence rule. First, in circumstances corresponding to the standard model of negligence under uncertainty, the prevailing negligence rule provides incentives for inefficient precaution. Allowing a defense of second-order reasonableness would restore incentives for efficient precaution in those cases where defendants can make their second-order precaution observable. Second, allowing this defense can encourage activities with positive externalities that tort liability otherwise discourages. Third, this defense can prevent actors from substituting worse forms of precaution for better ones, as sometimes happens when machines substitute for people, or when activities requiring risky judgments substitute for activities requiring risky execution. 